References

Brown, G. W., Bone, M., Dalison, D. \& Wing, J. K. (1966) Schizophrenia and Social Care. Maudsley Monograph No. 17. London: Oxford University Press.

HIRsch, S. R. \& Lefr, J. P. (1975) Abnormalities in Parents of Schizophrenics. Maudsley Monograph No. 22. London: Oxford University Press.

Tarrier, N., Vauohn, G., Lader, M. H. \& Lemp, J. P. (Submitted to Nature) Bodily reactions to people and events in schizophrenics.

\section{BEHAVIOUR THERAPY}

Dear Sir,

Readers of Dr Hafner's paper (Journal, 1976, 129, p 378-83) might wonder whether the conclusions drawn come from the data presented. He states that 'About 18 per cent of patients were adversely affected by the treatment programme', . . . that 'barely two-thirds of the 39 patients benefited usefully from treatment, and the emergence of fresh symptoms was a significant problem', and 'it is inescapable that a proportion of patients who received a standard symptomatic treatment were worse one year later'.

Tables I and II in the paper show improvement in all three groups on 4 of the 5 measures given. Although we are told that at one-year follow-up Group 3 was worse on 3 out of 4 measures, excluding symptoms directly treated, these are not specified, and the tables supplied actually depict slight improvement which is probably within chance levels (MHQ $56 \cdot 8$ to $55 \cdot 3$, FSS $74 \cdot 8$ to $70 \cdot 5$, self-dissatisfaction 13.5 to $12 \cdot 1$ ); on the only measure which seemed to imply a deterioration this change was within chance limits (spouse-dissatisfaction $7 \cdot 0$ to $8 \cdot 2, P<0 \cdot 1$ ). On what criteria, therefore, were Group 3 worsened, apart from a non-significant change on a rating scale of spouse-dissatisfaction whose reliability and validity has not been presented, and despite improvement in 4 other measures? To proceed from a non-significant change on 1 out of 5 measures which is in the opposite direction to all other measures given, and then to draw conclusions about 'worsening' seems illogical.

This aside, the definition of 'symptom emergence' is questionable: 'an increase over pre-treatment scores on any scale of the MHQ of Fear Survey Schedule on more than one of the 5 post-treatment assessments.' Fluctuations in severity of agoraphobia without treatment have been so well documented that 'fresh' symptoms need to be clearly beyond the natural fluctuation. Nevertheless, patients who before treatment had rather poorer marriages exposed themselves significantly less to the phobic situation, and after treatment did less well than other patients.

I agree with Dr Hafner's point that we should seek evidence of worsening in wide areas of a patient's functions after direct treatment of a specific problem. In a study of group exposure (flooding) for agoraphobics this was done (Hand et al, 1974): marital and interpersonal relationships for a group of 25 patients as a whole improved significantly, and the gain continued at follow-up. Seven patients had to be offered help for marital difficulties; however, twothirds of the 21 married patients regarded their marriages as unsatisfactory before treatment. This emphasizes that far from treatment being responsible for making marital discord 'emerge' or become 'substituted' for phobias, improvement in phobias and obsessions spills over as improvement in other areas. In a prospective follow-up study of phobic disorders 4 years after treatment, patients who improved most in their phobias showed least subsequent depression, and the group as a whole showed no worsening of general anxiety, obsessions, depersonalization, work, social, sexual, family, or other relationships (Marks, 1971).

Briefly, Dr Hafner's data illustrate the welldocumented phenomenon that patients who improve after behavioural treatment for a main problem, tend to improve in other areas, thus negating traditional ideas about symptom substitution.

Institute of Psychiatry,

RIGHARD STERN

\section{De Crespigny Park, \\ Denmark Hill, SE 5 8AF}

\section{References}

Hand, I., Lamontagne, Y. \& Marks, I. M. (1974) Group exposure (flooding) in vivo for agoraphobics. British Fournal of Psychiatry, 124, 588-602.

Marks, I. M. (197I) Phobic disorders 4 years after treatment. British Foumal of Pychiatry, 118, 683-8.

\section{Dear Sir,}

Reading Dr Hafner's article, we are deeply concerned at the methodology employed and the lack of understanding of the principles of behaviour therapy shown by the author. We will very briefly support our criticism.

\section{Methodology}

(a) There is a lack of information concerning the treatment involved. Who took the patients into the frightening situations; was the exposure graded (gradual approach) or was the flooding technique used?

(b) The patients are divided on the basis of results arising from two questionnaires which are then transformed into a score and used for statistical analysis. It is not clear whether the increases within 
each item were used, or differences between the total. One cannot add scores based on different scales.

(c) The author claims that half of the patients in Group 3 did improve, while the other half got worse. If this was the case, it would have been essential to reexamine the original assessment of the six patients who deteriorated.

(d) It is not stated whether the tests were related or unrelated. It is hoped that the related test was used.

\section{Theoretical assumptions}

In the Introduction, the author contrasts behaviour therapy with psychotherapy and claims to investigate standard treatment for agoraphobia. It is a known fact that there is no standard treatment for any phobia, least of all in agoraphobia, where fear of going out is usually only one of the many complaints and not necessarily the most important one.

What Dr Hafner does is to disregard individual differences and to administer a package to a heterogeneous sample. It is within the author's right to administer his treatment programme, but to suggest that this is standard behaviour therapy practice, and to make far-reaching conclusions on the basis of his study, is not acceptable. Behaviour therapy as a technology which leads to psychiatric diagnosis followed by a package deal treatment has a very limited application. It is essential to tailor treatment to the individual on the basis of behaviouristic analysis, which is guided by learning principles derived from relatively well-established findings in experimental psychology. Such analysis will lead to different treatments for the same diagnostic categories and will lead to the possibility of treatment of any complaint whether 'symptomatic' or 'underlying'.

The only difference between psychotherapy and behaviour therapy is in our view, the way both assessment and treatment are structured. Behaviour therapy would soon come to an unhappy end if treatment for agoraphobics consisted of nothing else but taking people on walks.

\section{Victor MEyer} BEN REICH

Academic Department of Psychiatry, Middlesex Hospital Medical School, London $W_{I} P$ 8AA

\section{Dear Sir,}

I respond to the letters of Dr Stern and of Drs Meyer and Reich. In my paper I suggest ( $p$ 378) that the resolution of the question of 'symptom substitution' was '... hindered by dogmatic and exaggerated statements on both sides, as well as by a lack of reliable data'. The letters to which I am responding seem to demonstrate the truth of this. They appear to be used mainly as vehicles for putting forward the authors' own views on behaviour therapy, at the price of idiosyncratic interpretations of my paper.

For example, Dr Stern quotes me as saying 'barely two-thirds of the 39 patients benefited usefully from treatment ... ' without mentioning that the context

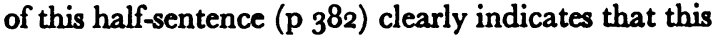
is one possible viewpoint, and not my own.

Drs Meyer and Reich suggest that my therapy . . . consisted of nothing else but taking people on walks', even though I stated ( $p$ 379) that '. . . each patient's post-treatment programme took into account progress made during treatment and allowed for any revision of initial treatment goals judged to be necessary'. They misconstrue my use of the term 'a standard intensive symptomatic treatment programme' as implying that the programme used is the treatment of choice for all agoraphobics, even though I clearly indicate my reservations about this type of treatment approach (p 382): 'If a standard group treatment programme makes a proportion of patients worse, can it be justified ethically . . .?'

Regarding their comment under (a), a detailed description of the treatment is given in the separate report mentioned in the text and listed in the references.

Space permits a response to only two specific criticisms of my data analysis. Regarding comment (b) of Drs Meyer and Reich, it seemed more accurate to use the total incidence of reported fresh symptom emergence as a basis for forming the three groups, rather than scores on just one of the symptom questionnaires. Once the three groups were formed, the questionnaires were analysed separately, as is shown clearly in Table I.

Regarding paragraph 2 of Dr Stern's letter, contrary to his statement that $I$ have not specified the symptoms directly treated, these are described in some detail ( $\left.p 3^{81}\right)$ as being reflected in the phobic anxiety scale of the MHQ and the A and B scales of the FSS.

Both letters appear to reflect an inability to acknowledge that behaviour therapy, whether based on exposure in real life or on so-called 'behaviouristic analysis', can make a proportion of people worse. It is naturally (as it was for me) painful for any therapist to acknowledge this, particularly if he wishes to emphasize the virtues of his own treatment approach in relation to that of others. But only by admitting that behaviour therapy may have adverse effects can the explanation for these be sought, and treatment modified.

In my study, those patients who deteriorated or failed to improve usefully were often married to 